\title{
Letramento Financeiro: Um Diagnóstico de Saberes Docentes
}

\author{
Financial Literacy: A Diagnosis of Knowledge Teachers
}

\author{
Cileda de Queiroz e Silva Coutinho \\ cileda.coutinho@gmail.com
}

James Teixeira

jteixeira@faap.br

\begin{abstract}
Resumo
O trabalho a seguir apresenta e discute os resultados de uma pesquisa realizada com um grupo de 161 professores voluntários, afim de diagnosticar o letramento financeiro de professores de Matemática que atuam no Ensino Médio. A partir das respostas obtidas no questionário aplicado ao grupo, a hipótese levantada é a de que a educação financeira só é alcançada quando trabalhada por um grupo de professores letrados financeiramente. Isso implica em que estes conheçam e dominem os conceitos de matemática financeira, disciplina fundamental para o ensino e a aprendizagem da educação financeira em conformidade com a Estratégia Nacional de Educação Financeira (ENEF), instituída pelo governo federal por meio do Decreto 7.397/10. A metodologia utilizada foi a Análise Estatística Implicativa (ASI), que buscou responder a hipótese da pesquisa por meio do exame de árvores de coesão e grafos implicativos. Entre os resultados observados, destacamos a percepção da matemática financeira como sendo praticamente o mesmo que a educação financeira, explicando assim as dificuldades observadas em pesquisas anteriores para a discussão crítica dos elementos contextuais de um problema envolvendo os temas abordados.
\end{abstract}

Palavras-Chave: Educação Financeira. Matemática Financeira. Análise Estatística Implicativa.

\begin{abstract}
This paper presents and discusses the results of research that sought to diagnose the mathematics teachers of financial literacy that operate in high school. A questionnaire was applied to a group of 161 volunteer teachers. The hypothesis is that financial education is achieved only when crafted by a group of literate teachers financially. This implies that these familiar with and master the concepts of financial mathematics, basic subject in the teaching and learning of financial education in accordance with the National Strategy for Financial Education (ENEF), established by the federal government, through Decree 7,397 / 10 . The methodology used was the Statistical Analysis Implicative (ASI) that sought to answer the hypothesis of the research by examining cohesion trees and truly implication graphs. Among the observed results, we highlight the perception of financial mathematics as being much the same thing that financial education, which may explain of the difficulties observed in previous research to critical discussion of the contextual elements of a problem involving financial education.
\end{abstract}

Key-words: Financial Education. Financial Math. Statistical Analysis Implicative.

\section{Introdução}

Evidencia-se a necessidade de se desenvolver a educação financeira desde o início da Escola Básica. Mas afinal o que é isso? Resumidamente, pode-se entendê-la como um conjunto de informações básicas sobre como fazer a melhor gestão do próprio dinheiro, o que envolve 
elaborar e acompanhar o orçamento pessoal ou familiar, comprar, poupar, investir e, de modo geral, usar o dinheiro de forma eficaz visando atingir objetivos mais rapidamente.

Silva (2004) alerta que a falta de uma cultura ampla de planejamento privou os brasileiros de conhecerem a real importância da gestão financeira pessoal para sua própria qualidade de vida. A boa educação financeira, consequentemente, promove a gestão dos recursos existentes e mantém o equilíbrio entre a razão e a emoção na hora de consumir, assumindo o poder de cada um em suas escolhas e na construção de novos conhecimentos, além de desenvolver a capacidade criativa para transformar recursos.

Para transformar o dinheiro em um importante aliado é necessário realizar um planejamento financeiro que envolve operações financeiras, como empréstimos, aplicações e resgates, com uma finalidade específica que, se bem direcionada, de acordo com Sá (2008), garante melhores resultados financeiros. O que leva a endender o planejamento como sendo o estabelecimento de metas factíveis.

Estas noções tomadas como base de aprendizagem favorecem que o aluno atribua significado aos cálculos realizados na abordagem dos conteúdos de matemática financeira, potencializando o desenvolvimento de sua educação financeira.

Para Tommasi e Lima (2007), a realização de um planejamento financeiro compreende a composição de um orçamento e ter habilidade para ter o endividamento como aliado. Assim sendo, acredita-se ser oportuna a discussão acerca do ensino da matemática financeira sob dois aspectos: a sua relação direta com temas da matemática escolar, tais como proporções, médias, porcentagens, progressões, funções e logaritmos, bem como a possibilidade de os seus conteúdos serem utilizados no processo de melhoria dos direitos sociais e no papel da cidadania sob uma perspectiva crítico-reflexiva.

Ressalta-se, finalmente, a iniciativa do governo federal ao publicar no Diário Oficial da União em 26 de dezembro de 2010 o decreto (7.397/10), instituindo a Estratégia Nacional de Educação Financeira (ENEF), cujo objetivo é promover a educação financeira e previdenciária contribuindo para o fortalecimento da cidadania, a eficiência e solidez do sistema financeiro nacional e a tomada de decisões conscientes por parte dos consumidores.

Nesse contexto, a pesquisa apresentada neste artigo teve como objetivo principal identificar elementos do letramento financeiro de professores que lecionam matemática no Ensino Médio, de modo que possam conduzir seus alunos no desenvolvimento da educação financeira. 
Educação Financeira e Letramento Financeiro

A Educação Financeira não consiste tão somente em aprender a economizar, cortar gastos, poupar e acumular dinheiro. Na verdade é buscar uma melhor qualidade de vida tanto hoje quanto no futuro, proporcionando a segurança material necessária para obter uma garantia para eventuais imprevistos. Tendo como pano de fundo o crescimento econômico e a maior distribuição de renda no Brasil, a oferta de crédito consequentemente cresceu junto ao poder de aquisição da população. Evidentemente que esse fato é positivo, porque se traduz em maior qualidade de vida, realizações de sonhos, educação e satisfação pessoal. Todavia é preciso que esse consumo seja planejado, estudado e a facilidade de crédito analisada, pois esta "facilidade" pode implicar em um acúmulo de dívidas e descontrole da vida financeira.

Vale lembrar que aspectos sociais e econômicos mudaram significativamente nos últimos anos. Entre 2002 e 2007, a classe média saltou de 32\% para 47\% da população total, incorporando mais 23,5 milhões de pessoas. Além disso, a pobreza extrema regrediu de quase $12 \%$ para 5\% da população entre 1992 e 2007, ou seja, um decréscimo de quase $60 \%$. Ao mesmo tempo, a disparidade na distribuição de renda no Brasil, tradicionalmente alta, passou por modificações significativas.

Assim sendo, uma gama crescente de produtos financeiros (empréstimos, poupanças, investimentos, seguros e planos de pensão) oferecidos aos consumidores veio acompanhada de mais responsabilidade em suas escolhas. Essa complexidade torna as decisões mais difíceis, já que é necessário comparar as características de cada opção para fazer escolhas conscientes, tais como: aquisição da casa própria, acesso à educação, compra de bens e serviços, entre outras.

Para transformar o dinheiro em um importante aliado é necessário realizar um planejamento financeiro, que envolve operações financeiras, como: empréstimos, aplicações e resgates com uma finalidade específica, que se bem direcionadas, de acordo com Sá (2008), garante melhores resultados financeiros. Entende-se assim o planejamento como sendo o estabelecimento de metas factíveis.

No que se refere ao letramento financeiro ou literacia financeira, definiremos primeiramente a literacia (ou letramento) de uma forma mais geral. A Organização das Nações Unidas para a Educação, a Ciência e a Cultura (UNESCO) define literacia como a capacidade para identificar, compreender, interpretar, criar, comunicar e usar novas tecnologias, de acordo com os diversos contextos; envolve um processo contínuo de aprendizagem que permite que 
os indivíduos alcancem os seus objetivos, desenvolvam o seu conhecimento, as suas potencialidades e participem de forma plena na comunidade e de forma mais ampla na sociedade (UNESCO, 2005). Nesse sentido, assumimos como letramento financeiro a capacidade de identificar, compreender, interpretar, criar e usar novas tecnologias em contextos relativos ao tratamento de problemas que envolvam planejamento e gerenciamento de finanças pessoais.

Concordamos com o defendido pela OCDE (2004), para quem é reconhecida mundialmente a educação financeira como uma competência necessária para a vida das pessoas e uma componente chave para a estabilidade e o desenvolvimento econômico (OCDE, 2004).

É importante destacar a íntima relação existente entre a educação financeira e o letramento financeiro, haja vista que a maioria das definições de educação financeira invoca a ideia de aumentar o letramento por meio do fornecimento de competências relacionadas à compreensão, poder de escolha e de decisão nas áreas das finanças pessoais (compreensão dos produtos e dos serviços financeiros e suas respectivas características).

Ressaltamos a questão da inclusão financeira, pois o acesso aos serviços financeiros está relacionado com os conhecimentos da população relativamente a serviços bancários básicos. Um estudo do Instituto Mundial dos Bancos de Poupança, denominado "Access to Finance Resolution", publicado em 2004, concluiu que a exclusão financeira nos países em desenvolvimento se deve à falta de conhecimento sobre questões relacionadas com o dinheiro em geral. Neste sentido, a educação financeira é vista como uma estratégia para aumentar a inclusão financeira, uma vez que uma conta bancária permite uma melhor gestão do rendimento e um maior controle dos gastos. Ou seja, o desenvolvimento do letramento financeiro permite a construção de uma educação financeira que favorece a inclusão.

Pesquisas na área

A construção dos itens do questionário utilizado em nossa pesquisa foi subsidiada, fundamentalmente, por resultados de pesquisas na área. Em busca no Banco de Teses da CAPES, assim como publicações na revista Zetetiké e no site da Sociedade Brasileira de Educação Matemática (SBEM), com as palavras-chave "educação financeira" e "educação matemática”, encontramos 32 trabalhos, entre os quais oito deles tratavam da formação de professores para esse tema. 
Tais resultados ressaltaram itens como a importância do contexto na apresentação do tema, visando a distinção entre educação financeira e matemática financeira (SCHENEIDER, 2008; HERMÍNIO, 2008; GRANDO E SCHENEIDER, 2010; HOFFMANN, 2011; HOFFMANN E MORO, 2012). Os resultados de Ribeiro et Al (2009) também indicam a importância do contexto, uma vez que tratam do endividamento em contexto de um curso de administração.

Outro resultado importante assinalado nas pesquisas refere-se à abordagem, indicando que a metodologia da resolução de problemas e a consideração das novas linguagens e modelos matemáticos tão presentes no mundo dos educandos favorece a atribuição de significados (ROSSETI JUNIOR E SCHIMIGUEL, 2009).

Verificou-se também a importância de que os conteúdos, as estratégias e a análise crítica provenientes da matemática financeira, além da descrição de algoritmos, fórmulas e cálculos descontextualizados, favorecem uma educação matemática que estimula a investigação e o espírito crítico do aluno/cidadão (PELICIOLI, 2011). O uso das tecnologias também foi destacado em alguns dos resultados observados por esse autor.

Vale destacar que alguns dos resultados encontrados em pesquisas sobre educação financeira que tratavam da aprendizagem (foco no aluno) também forneceram elementos para nossa pesquisa, como poderá ser observado na análise dos nossos dados.

Sintetizando, um problema que permeia as pesquisas é a observação de que o professor de matemática não recebe ou pouco recebe uma formação específica em matemática financeira. Pelo fato de o ensino da educação financeira se encontrar em fase de implementação no Brasil, seguindo os exemplos dos Estados Unidos, Europa e Japão, se faz necessário melhorar a formação dos professores que lecionam matemática financeira, objetivando conectar essa disciplina à educação financeira.

Outro aspecto relevante observado nas pesquisas é a importância da história econômica e da evolução do mercantilismo no mundo. Os pesquisadoes afirmam que a sua abordagem e o seu ensinamento realçam o ensino da matemática financeira na medida em que o professor pode, além de ampliar a cultura dos alunos, estabelecer relações entre o passado e o presente.

Finalizando, vale ressaltar que os resultados apontam para a necessidade de desenvolver estratégias fundamentadas em teorias didáticas que possam levar ao estreitamento das relações entre educação matemática e educação financeira. Essa tarefa vem sendo um desafio para pesquisadores, educadores e gestores da educação, na perspectiva de proporcionar a evolução plena dos jovens no contexto educacional brasileiro. 


\section{Referencial teórico-metodológico}

A análise estatística implicativa (Analyse Statistique Implicative - ASI) é um método de análise de dados que opera sobre um conjunto de valores numéricos não negativos (GRAS; KUNTZ; BRIAND, 2001). Ela cruza um conjunto $\mathrm{E}$ de $\mathrm{n}$ sujeitos e um conjunto $\mathrm{V}$ de variáveis binárias (por exemplo, atributos), numéricas (por exemplo, modais), intervalares (por exemplo, difusas) ou vetoriais (por exemplo, sequências). Tais variáveis são chamadas principais ou ativas e elas refletem o comportamento, ou a atitude dos sujeitos. Os descritores ou variáveis que caracterizam os elementos do conjunto $\mathrm{E}$ de indivíduos são chamados de variáveis suplementares.

Dessa forma, o cruzamento das variáveis ativas permite identificar comportamentos caracterizados por elas, formando agrupamentos ou "clusters", a serem analisados à luz do contexto no qual os dados foram coletados e dos referenciais construídos. Por meio da ASI podemos identificar as características dos sujeitos que compõem tal agrupamento, sinalizando as tipicalidades a partir das variáveis suplementares.

Neste texto, a ASI terá por objetivo identificar uma classe cujas variáveis ativas escolhidas são destinadas para estudar os conhecimentos docentes sobre os princípios da educação financeira. Tais variaveis indicam um comportamento de negação do uso de problemas contextualizados para a realidade do aluno, uma vez que essa utilização implica no conhecimento sólido da realidade pelo professor.

A ASI permite revelar, por meio de cálculos probabilísticos, quais são os professores com tempo de magistério menor do que cinco anos e que formam o grupo típico dessa classe.

No que se refere ao tipo de relações identificadas, esta metodologia parte do pressuposto que os operadores de implicação são usados para implementar regras de inferência (limitações relacionais) do tipo: "Se (premissa), então (conclusão)". Sendo assim, para verificar até que ponto a premissa implica na conclusão dados os valores reais, torna-se possível constatar o grau de implicação a partir de cálculos probabilísticos feitos sobre uma variável aleatória bem determinada com distribuição binomial ou de Poisson, como afirmam Gras, Kuntz e Briand (2001).

A análise estatística implicativa, possibilitada pelo software de classificação hierárquica implicativa e coesitiva (CHIC), é um método estatístico multidimensional que possibilita uma análise de agrupamentos formados a partir de critérios probabilísticos específicos, construídos 
com base na distribuição binomial (no caso desta tese, pelo uso de amostra menor do que 1.000 sujeitos).

Para os propósitos da pesquisa que deu oriegem a esse trabalho, decidiu-se que a abordagem e a estruturação dos dados fossem feitas de forma binária (presença ou ausência do atributo). Para o banco de dados construído a partir das respostas dos sujeitos ao questionário aplicado, decidiu-se pelas análises acerca da classificação coesitiva, bem como dos gráficos implicativos que visam identificar as relações qualitativas existentes. A análise de similaridades não propiciou resultados discriminatórios.

Segundo Almouloud (2005), a análise estatística implicativa pode ser utilizada em pesquisas na área da educação e da educação matemática com o objetivo de tomar decisões que se apoiam em certa estabilidade e pertinência de respostas.

Os dados coletados foram organizados em tabelas e gráficos, segundo a filosofia da análise exploratória de dados (variáveis consideradas de caracterização dos respondentes). As variáveis consideradas ativas (expressam as opiniões fornecidas pelos respondentes sobre os temas perguntados) receberam tratamento estatístico multidimensional, embora sempre que se julgou necessário, estas variáveis também foram estudadas segundo a análise exploratória de dados.

A análise estatística implicativa tem seus resultados representados por meio de dendogramas ou de grafos que agrupam as variáveis inter-relacionadas em classes, a partir de níveis evidenciados como mais significativos em relação aos cálculos probabilísticos que fundamentam tais associações (GRAS; ALMOULOUD, 2002).

O banco de dados da pesquisa aqui citada foi organizado segundo dois critérios, de forma a viabilizar a análise: respostas referentes à investigação do nível de letramento dos professores, e respostas correspondentes à percepção sobre a presença de conteúdos de matemática financeira nos livros didáticos utilizados pelos docentes pesquisados.

Discussão dos resultados

Foram coletados dados por meio de questionário composto de 30 questões, aplicado a 161 professores que ministram conteúdos de matemática financeira em suas aulas de Matemática, base do desenvolvimento da educação financeira. A primeira parte era composta por itens que visavam a caracterização dos sujeitos, enquanto que a segunda parte trazia itens que tinham 
por objetivo diagnosticar elementos do letramento financeiro e da forma de utilização do livro didático para abordagem da Matemática Financeira.

Figura 1: Itens da parte 2 do questionário

$\left.9^{a}\right)$ Quando você fez a sua graduação, teve a disciplina de Matemática Financeira?

10 ${ }^{a}$ Em suas aulas, você costuma abordar os conteúdos de Matemática Financeira sugeridos nos livros didáticos? (resposta em escala de quatro níveis)

$\left.11^{a}\right)$ Em suas aulas, você se preocupa em contextualizar os exemplos e os exercícios abordados no tema de Matemática Financeira? (quatro opções de resposta)

As questões 12, 13, 14 foram respondidas por escala de quatro níveis.

12a) Você concorda com a afirmação de que o livro didático orienta adequadamente o professor para o uso de calculadoras elou planilhas eletrônicas nas aulas em que a Matemática Financeira será trabalhada?

13 $\left.{ }^{a}\right)$ Você costuma utilizar recursos tecnológicos (planilhas eletrônicas, emuladores, calculadoras financeiras, etc.) ao abordar Matemática Financeira?

14a) Ao preparar sua aula de Matemática Financeira, você procura conhecer resultados de pesquisas recentes desse tema?

15 ) Você sabia que a Educação Financeira é ensinada às crianças e adolescentes em países desenvolvidos da Europa, Japão e Estados Unidos? (sim-não)

16 $\left.{ }^{a}\right)$ Você conhece a ENEF (Estratégia Nacional de Educação Financeira), instituída pelo Decreto ${ }^{o}$ 7.397 de 22 de dezembro de 2010, a qual tem a finalidade de promover a Educação Financeira para o fortalecimento da cidadania? (sim-não)

17') Você acredita que a Matemática Financeira e a Educação Financeira são: A mesma coisa; Quase a mesma coisa; Muito diferentes

As questões 18 a 29 foram respondidas por escala de quatro níveis.

$18^{a}$ ) Utiliza fórmulas fornecidas pelos livros didáticos?

19a) Utiliza fórmulas, mas conduz os alunos à dedução?

$\left.20^{a}\right)$ Parte do estudo das funções linear e exponencial para chegar às fórmulas de Juros Simples e Juros Compostos?

$\left.21^{a}\right)$ Parte do estudo de outros tópicos da Matemática para chegar às fórmulas de Juros Simples e Juros Compostos?

22a) Primeiro explica as noções envolvidas para depois propor situações-problema?

23a) Propõe situações-problema construídas a partir de diálogos com os alunos?

24a) Propõe situações-problema para complementar os livros didáticos?

25 $5^{a}$ Utiliza exatamente o proposto pelos livros didáticos?

$\left.26^{a}\right)$ Compara situações nas quais se usa juros simples com situações de juros compostos?

$\left.27^{a}\right)$ Solicita aos alunos que busquem exemplos de situações nas quais se empreguem juros simples?

28) Solicita aos alunos que busquem exemplos de situações nas quais se empreguem juros compostos?

29a) Solicita aos alunos que busquem exemplos que coloquem em confronto a utilização de Juros Simples e Compostos?

$\left.30^{a}\right)$ Uma pessoa precisa de $R \$$ 1.200,00 para pagar uma despesa inesperada. Para conseguir pagar tal despesa, faz um empréstimo com seu tio, que lhe cobrará 1\% por mês que essa pessoa demora para lhe pagar, sendo que esse valor será calculado sempre sobre os $R \$ 1.200,00$ iniciais. Pergunta-se:

a) Qual o valor cobrado a cada mês que a pessoa demora para devolver o dinheiro ao tio?

b) Se a pessoa demora três meses para pagar ao tio que lhe emprestou, qual o valor além dos $R \$$ $1.200,00$ que deverá desembolsar?

c) Qual o valor total a ser desembolsado ao final desses três meses para o pagamento da divida com esse tio? 
d) Supondo que o valor emprestado seja igual a $P$ e que a porcentagem cobrada seja igual a $i$, calculada sempre sobre o valor emprestado $P$, e que o empréstimo será pago ao final de n meses, que expressão matemática pode expressar essa operação financeira?

Os resultados indicam que 65,84\% dos professores participantes possuem Licenciatura em Matemática e estavam alocados em escolas de cinco cidades no Estado de São Paulo ao longo do primeiro semestre de 2014: Barueri, São Paulo, Sorocaba, Osasco e São José dos Campos. Vale destacar que estes municípios foram escolhidos por um critério de acessibilidade, sem a utilização de metodologias probabilísticas.

A Figura 2 ilustra a distribuição dos professores quanto ao tempo de magistério. Observamos uma distribuição quase uniforme entre as faixas estabelecidas para essa contagem, o que pode significar posições bastante distintas no grupo, de acordo com Huberman (1974 apud BOLIVAR, 2002): a primeira coluna do gráfico representa professores em início de carreira e em fase de consolidação do repertório pedagógico; a segunda coluna representa os professores em fase de diversificação, ativismo ou redelineamento; terceira e quarta colunas representam ambas professores em fase de conservadorismo ou de serenidade. Nesse sentido, podemos inferir uma atitude positiva frente à Educação Financeira em cada uma dessas fases, uma vez que esses professores responderam voluntariamente ao questionário, sabendo seu conteúdo. No entanto, vale ressaltar que para aqueles que se encontram em fase de conservadorismo ou mesmo de ruptura (acima de 30 anos de magistério), esse tempo pode significar resistência quanto a novas propostas curriculares, como é o caso da inserção da educação financeira no currículo da matemática do Ensino Médio.

Figura 2: Distribuição dos professores respondentes quanto ao tempo de magistério

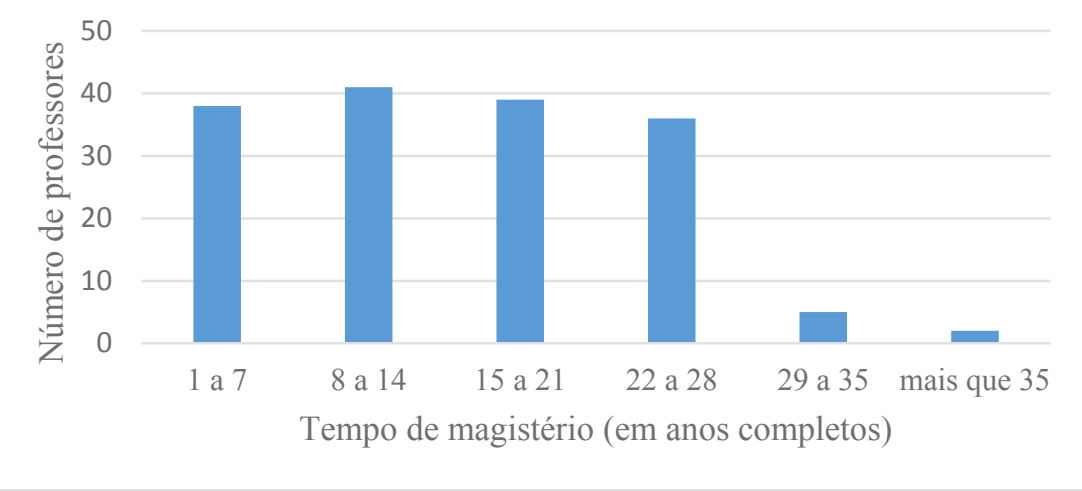

Fonte: dados da pesquisa ${ }^{1}$

\footnotetext{
${ }^{1}$ Todas as tabelas e gráficos (figuras) foram construídos a partir dos dados coletados na pesquisa. Dessa forma, não indicaremos a fonte de cada um desses elementos, já que esta se repete.
} 
No que se refere ao número de aulas semanais, observa-se que 46,58\% dos professores declaram ministrar entre 18 e 26 aulas semanais, sendo que, entre os 161 respondentes, $87,58 \%$ apontam ter até 26 aulas semanais. Sabe-se que segundo a lei $\mathrm{n}^{\mathrm{o}} 11.738$, de 16 de julho de 2008 , em seu artigo $2^{\circ}, \S 4^{\circ}$, um professor terá um máximo de dois terços de seu contrato para atividades em sala de aula, ou seja, aproximadamente 26 horas no caso de um contrato de 40 horas semanais. Não é difícil inferir que quanto maior o número de horas em sala de aula, menor é o tempo dedicado à atualização e ao preparo dessas aulas, o que converge para o já observado quanto às idades e tempo de magistério.

Caracterizados os professores que colaboraram com a pesquisa, nos itens que seguem discutiremos os resultados observados a partir da Análise Estatística Implicativa (ASI). Destes dados, faremos um recorte para os itens que nos permitiram inferir sobre o letramento financeiro dos professores pesquisados.

\section{Análise Coesitiva}

No que segue, analisamos as respostas dos professores no que se refere ao letramento financeiro por meio da análise coesitiva. Buscamos, por meio da análise dos agrupamentos e meta-regras identificadas, diagnosticar elementos de raciocínio compatíveis com a definição de letramento financeiro e de educação financeira que adotamos nessa pesquisa.

A primeira classe foi então analisada e suas subclasses apresentadas na Figura 3. Observamos que a subclasse destacada na figura, que começa em Q9r1 (estudou Matemática Financeira na graduação) e vai até Q30Cr1 (acertou o item c do problema 30), tem como característica a opção "sim" para os questionamentos e o acerto ao problema apresentado no item 30 do instrumento, em suas três fases. Neste conjunto de variáveis, a única que recebeu resposta "não", é apresentada no item Q16, que demandava se o professor conhecia ou não a ENEF. Para permitir a leitura da árvore, reproduzimos os itens do questionário que são agrupados.

Podemos efetuar a seguinte leitura para as meta-regras identificadas: se cursou matemática financeira em sua formação, então tem conhecimento que a educação financeira é ensinada em outros países. Se concorda com essas duas afirmações, então não conhece a ENEF. Se está nesse grupo, então acertou aos itens a, b e c da questão 30. Tais relações já fornecem indícios para a identificação de elementos do letramento financeiro, relacionados ao conhecimento de aspectos funcionais (legislação, aplicabilidade) assim como para a construção de hipótese referente ao conhecimento específico desse conteúdo (referente à sua formação inicial). 
Figura 3: Árvore coesitiva - subclasse classe A1

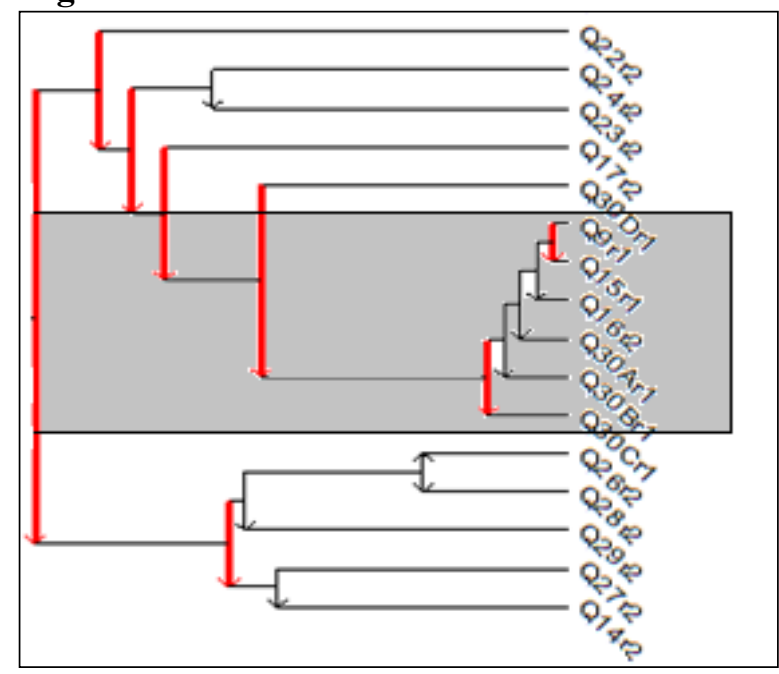

Pelicioli (2011) e Savoia, Saito e Santana (2007) levantam a questão da escassez de publicações e pesquisas acerca da presença e discussão de educação financeira no Brasil. Pode-se inferir que essa seja uma das causas do não conhecimento da ENEF pelos professores participantes.

Este grupo de professores resolveram corretamente a questão 30 . O grupo típico dessa classe é o formado pelos professores do sexo masculino, que trabalham em Barueri e que alegam ministrar 18 a 26 aulas semanais, com risco tendendo a zero. O risco, na análise coesitiva, indica a probabilidade de erro na identificação do grupo típico.

Observa-se também que nesta subclasse, todos os índices de coesão tendem a 1 (probabilidade de que a relação encontrada ocorra efetivamente). Ou seja, tal valor aponta a forte coesão nas regras estabelecidas para associação entre as variáveis que indicam elementos do letramento financeiro dos respondentes. O índice de coesão tendendo a 1 permite atribuir um significado bastante expressivo ao conjunto de associações (meta-regras) identificadas.

Quadro 1: Variáveis associadas hierarquicamente na subclasse A1

\begin{tabular}{|c|c|}
\hline \multicolumn{2}{|r|}{ (((((Q9r1 Q15r1) Q16r2) Q30Ar1) Q30Br1) Q30Cr1) Coesão : 1} \\
\hline Q9 r1 & Quando você fez a sua graduação, teve a disciplina de matemática Financeira? SIM \\
\hline Q15 r1 & $\begin{array}{l}\text { Você sabia que a Educação Financeira é ensinada às crianças e adolescentes em países desenvolvidos da Europa, Japão e Estados } \\
\text { Unidos? SIM }\end{array}$ \\
\hline Q16 r2 & $\begin{array}{l}\text { Você conhece a ENEF (Estratégia Nacional de Educação Financeira), instituída pelo Decreto nº } 7.397 \text { de } 22 \text { de dezembro de 2010, a qual } \\
\text { tem a finalidade de promover a Educação Financeira para o fortalecimento da cidadania? NÃO }\end{array}$ \\
\hline Q30 Ar1 & $\begin{array}{l}\text { Uma pessoa precisa de } \mathrm{R} \$ 1.200,00 \text { para pagar uma despesa inesperada. Para conseguir pagar tal despesa, faz um empréstimo com seu } \\
\text { tio, que Ihe cobrará } 1 \% \text { por mês que essa pessoa demora para lhe pagar, sendo que esse valor será calculado sempre sobre os } \mathrm{R} \$ 1.200,00 \\
\text { iniciais. Qual o valor cobrado a cada mês que a pessoa demora para devolver o dinheiro ao tio? ACERTOU }\end{array}$ \\
\hline Q30 Br1 & 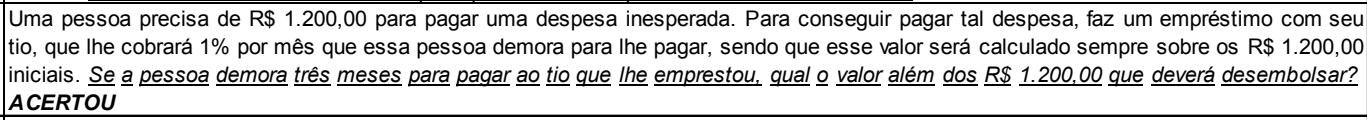 \\
\hline Q30 Cr1 & $\begin{array}{l}\text { Uma pessoa precisa de } \mathrm{R} \$ 1.200,00 \text { para pagar uma despesa inesperada. Para conseguir pagar tal despesa, faz um empréstimo com seu } \\
\text { tio, que Ihe cobrará } 1 \% \text { por mês que essa pessoa demora para Ihe pagar, sendo que esse valor será calculado sempre sobre os } \mathrm{R} \$ 1.200,00 \\
\text { iniciais. Qual o valor total a ser desembolsado ao final desses três meses para o pagamento da dívida com esse tio? } \text { ACERTOU }\end{array}$ \\
\hline
\end{tabular}


A Figura 4 mostra a ampliação da subclasse A1, incluindo relações que envolvem, consecutivamente, as questões 30 (acerto do item d), 17 (educação financeira e matemática financeira são quase a mesma coisa), 23, 24 e 22, estas com concordância parcial a aspectos relativos à abordagem pela resolução de problemas. Segundo o sentido estabelecido nas relações encontradas, se o professor utiliza algumas vezes situações contextualizadas, então algumas vezes completa o proposto pelo livro didático e busca discutir com os alunos sobre as situações abordadas. No entanto, afirmam que matemática financeira e educação financeira é quase a mesma coisa.

Figura 4: Árvore coesitiva - subclasse A2.

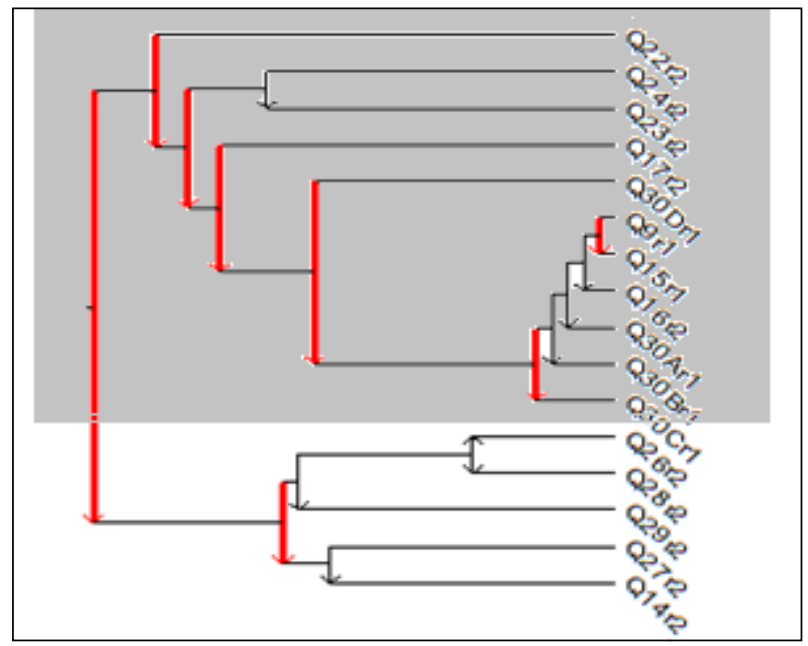

Essa situação vem ao encontro da posição de Duarte et al (2012), ao apresentarem pesquisa evidenciando melhor desempenho quando se estuda matemática financeira à luz de situações devidamente contextualizadas e de cunho realístico. Concordamos com a premissa de que o raciocínio financeiro e pragmático deve ser desenvolvido nos exemplos e exercícios propostos, ao se dialogar com os alunos a partir destas situações de cunho realístico, conduzindo-os a posições coerentes com os pressupostos da matemática crítica.

Ainda sobre a importância da contextualização ao se ensinar matemática financeira, Almeida (2004) e Vieira (2010) chamam a atenção para a necessidade da utilização de contextos adequados. Para estes autores, conhecimentos práticos e contextualizados ajudam a melhorar o ensino e a aprendizagem dessa disciplina.

Completando a análise das variáveis identificadas na classe ilustrada nas figuras 3 e 4, observemos a Figura 5. Dessa forma, teremos a classe A formada pelas classes A2 e A3, sendo que A1 está contida em A2, conforme já foi discutido nesse texto. 
Figura 5: Árvore coesitiva, subclasse A3.

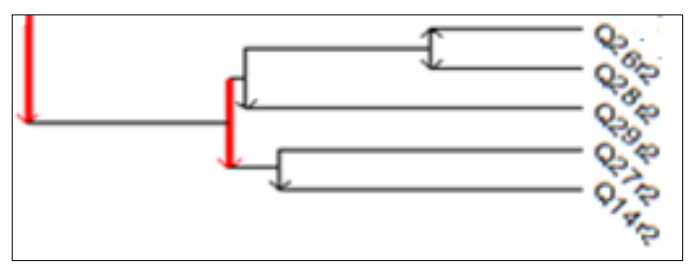

A subclasse A3 se caracteriza pela concordância parcial com os seguintes itens do questionário: 26 (compara situações de juros simples com situações de juros compostos), 28 (solicita aos alunos que busquem exemplos de juros compostos), 29 (solicita aos alunos que busquem exemplos que confrontem juros simples e compostos), 27 (solicita aos alunos que busquem exemplos de juros simples) e 14 (ao preparar aula, busca conhecer resultados de pesquisas na área). O índice de coesão nessa classe A3 é igual a 0,995, indicando a forte probabilidade de ocorrência das relações encontradas.

A classe B, cuja tipicalidade é o gênero feminino e apresenta um índice de coesão de 0,768 , traz características importantes a serem destacadas. Os professores aqui não tiveram a disciplina de matemática financeira e acreditam que ela e a educação financeira são a mesma coisa. O fato de eles dialogarem com os alunos frequentemente, propondo situações-problema envolvendo juros simples e compostos, pode explicar a ação desses mesmos professores em contextualizar tais situações baseados no cotidiano dos alunos.

Figura 6: Árvore coesitiva, classe B

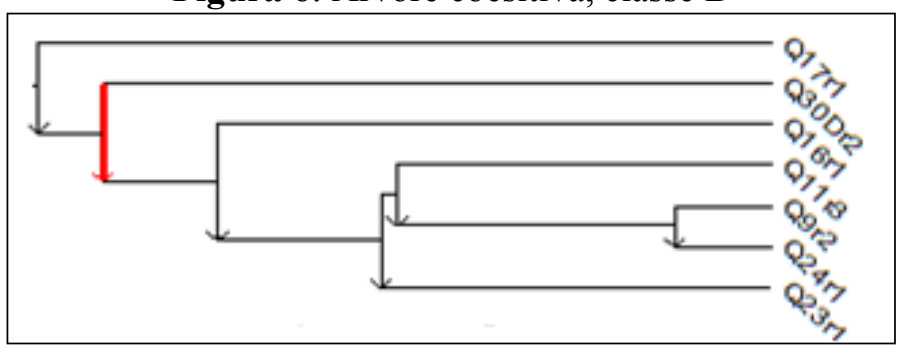

O trabalho de Stephani (2005) lembra que a construção da autonomia é favorecida por meio da forma participativa com que os alunos compartilham suas experiências entre eles e o professor. Assim como a pesquisa de Vieira (2010), ele associa e enfatiza a necessidade da contextualização do ensino da matemática financeira no dia a dia dos alunos do Ensino Médio articulado ao desenvolvimento da cidadania.

Por meio da análise da Figura 7, que retrata a classe C (índice de coesão de 0,999 ) podemos deduzir que aquele professor que frequentemente busca conhecer resultados de pesquisas 
acerca do tema matemática financeira, ao preparar a sua aula, solicita aos seus alunos um maior aprofundamento nessas questões feitas por meio de comparações e exemplos envolvendo juros simples e compostos. A variável típica dessa classe é o sexo feminino e professores que lecionam nos Municípios de Osasco e São José dos Campos.

Vale aqui destacar a contribuição de Kern (2009) ao ressaltar a necessidade da regularidade e aprofundamento do estudo da matemática financeira e a sua relação com a educação financeira de forma interdisciplinar.

Figura 7: Árvore coesitiva, classe C

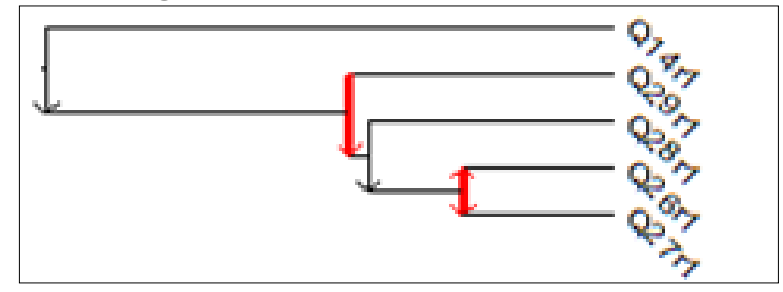

A tipicalidade da classe D é o sexo feminino. A partir da análise conjunta da Figura 8 e do Quadro 2, é possível inferir que sem iniciativas e proposituras pedagógicas feitas por parte do professor, podem haver prejuízos das competências cognitivas em relação ao aluno. Nesta classe, o índice de coesão é de 0,852 , representando o professor que nunca oferece exemplos ou propõe situações-problema envolvendo os regimes de capitalização, nunca pede aos seus alunos que façam pesquisas nessa área ou mesmo que não compara situações confrontando juros simples e compostos. Pode ter contribuído para estes fatos a não-resposta de nenhum item da questão 30 (problema proposto).

Figura 8: Árvore coesitiva, classe D

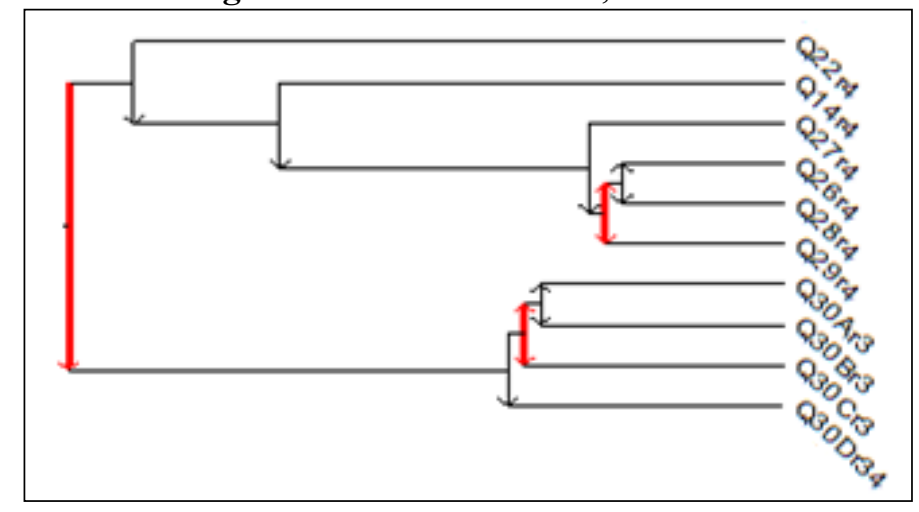

Kleiman (2005) destaca que o professor deve trabalhar com práticas sociais não escolares. A autora defende que o professor precisa ter conhecimentos necessários para agir como um verdadeiro agente social, um agente de letramentos - nas palavras dela: um gestor de saberes. 
Quadro 2: Variáveis associadas hierarquicamente formando a classe D

\begin{tabular}{|c|c|}
\hline \multicolumn{2}{|r|}{ ((Q22r4 (Q14r4 (Q27r4 ((Q26r4 Q28r4) Q29r4)))) (((Q30Ar3 Q30Br3) Q30Cr3) Q30Dr34)) Coesão : 0.852} \\
\hline Q22 r4 & Primeiro explica as noções envolvidas para depois propor situações-problema? NUNCA \\
\hline Q14 r4 & Ao preparar sua aula de Matemática Finaceira, você procura conhecer resultados de pesquisas recentes desse tema? NUNCA \\
\hline Q27 r4 & Solicita aos alunos que busquem exemplos de situações nas quais se empreguem Juros Simples? NUNCA \\
\hline Q26r4 & Compara situações nas quais se usa Juros Simples com situações de Juros Compostos? NUNCA \\
\hline Q28 r4 & Solicita aos alunos que busquem exemplos de situações nas quais se empreguem Juros Compostos? NUNCA \\
\hline Q29 r4 & Solicita aos alunos que busquem exemplos que coloquem em confronto a utilização de Juros Simples e compostos? NUNCA \\
\hline Q30 Ar3 & $\begin{array}{l}\text { Uma pessoa precisa de } \mathrm{R} \$ 1.200,00 \text { para pagar uma despesa inesperada. Para conseguir pagar tal despesa, faz um empréstimo com seu } \\
\text { tio, que lhe cobrará } 1 \% \text { por mês que essa pessoa demora para lhe pagar, sendo que esse valor será calculado sempre sobre os } \mathrm{R} \$ 1.200,00 \\
\text { iniciais. Qual o valor cobrado a cada mês que a pessoa demora para devolver o dinheiro ao tio? NÃO FEZ A QUESTÃO }\end{array}$ \\
\hline Q30 Cr3 & 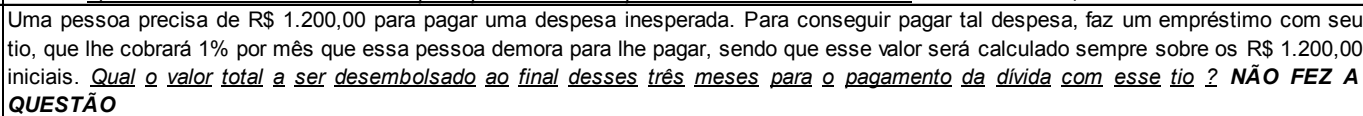 \\
\hline Q30 Dr3 & 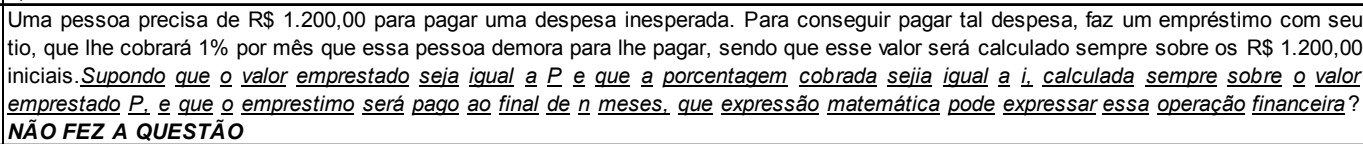 \\
\hline
\end{tabular}

Essa classe também denota aspectos merecedores de comentários e observações. Apresentando o índice de coesão de 0,739 com tipicalidade de professores com faixa etária entre 22 e 28 anos, a Figura 9 remete a inferir que o docente que raramente busca conhecer pesquisas recentes acerca de matemática financeira, também raramente solicita ao seu aluno que busque exemplos envolvendo os regimes de capitalização, bem como não compara, em suas aulas, situações de juros simples e compostos. Um dos prováveis motivos desse desinteresse pode ser explicado pelo desconhecimento acerca da importância do ensino e aprendizagem da educação financeira em outros países, ou mesmo pelas características tempo de magistério identificadas e analisadas segundo Huberman (1974 apud BOLIVAR, 2002).

Figura 9: Árvore coesitiva, classe E

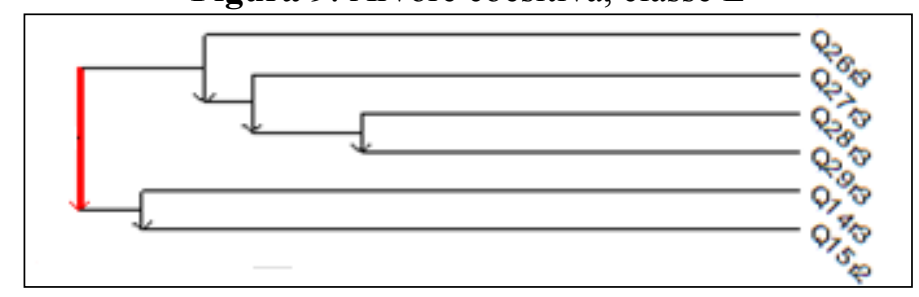

\section{Análise implicativa}

O grafo implicativo é uma representação das relações entre as variáveis consideradas em um certo fenômeno ou situação que está sendo estudado. No caso, o letramento financeiro dos respondentes. A análise das implicações entre as categorias de estudo introduz uma ideia de causalidade. No que se refere ao banco de dados construído a partir das respostas ao questionário aplicado, podemos observar as implicações ilustradas na Figura 10. Assim, essas relações de implicação ou quase implicação se apresentam como instrumentos para evidenciar concorrências e, mediante análise, permitir identificar as representações a ela associadas. Em outras palavras, os caminhos implicativos (CI), segundo o tratamento estatístico qualitativo 
realizado, buscam levantar o nível de causalidade entre as diversas variáveis envolvidas nesta pesquisa. As figuras 10 e 11 apresentam os caminhos implicativos relativos ao letramento financeiro analisado (Figura 10 representa o destaque indicado na Figura 11, para permitir a visualização das relações abordadas neste texto).

Figura 10: Grafo implicativo, letramento financeiro, com destaque para relações analisadas no texto

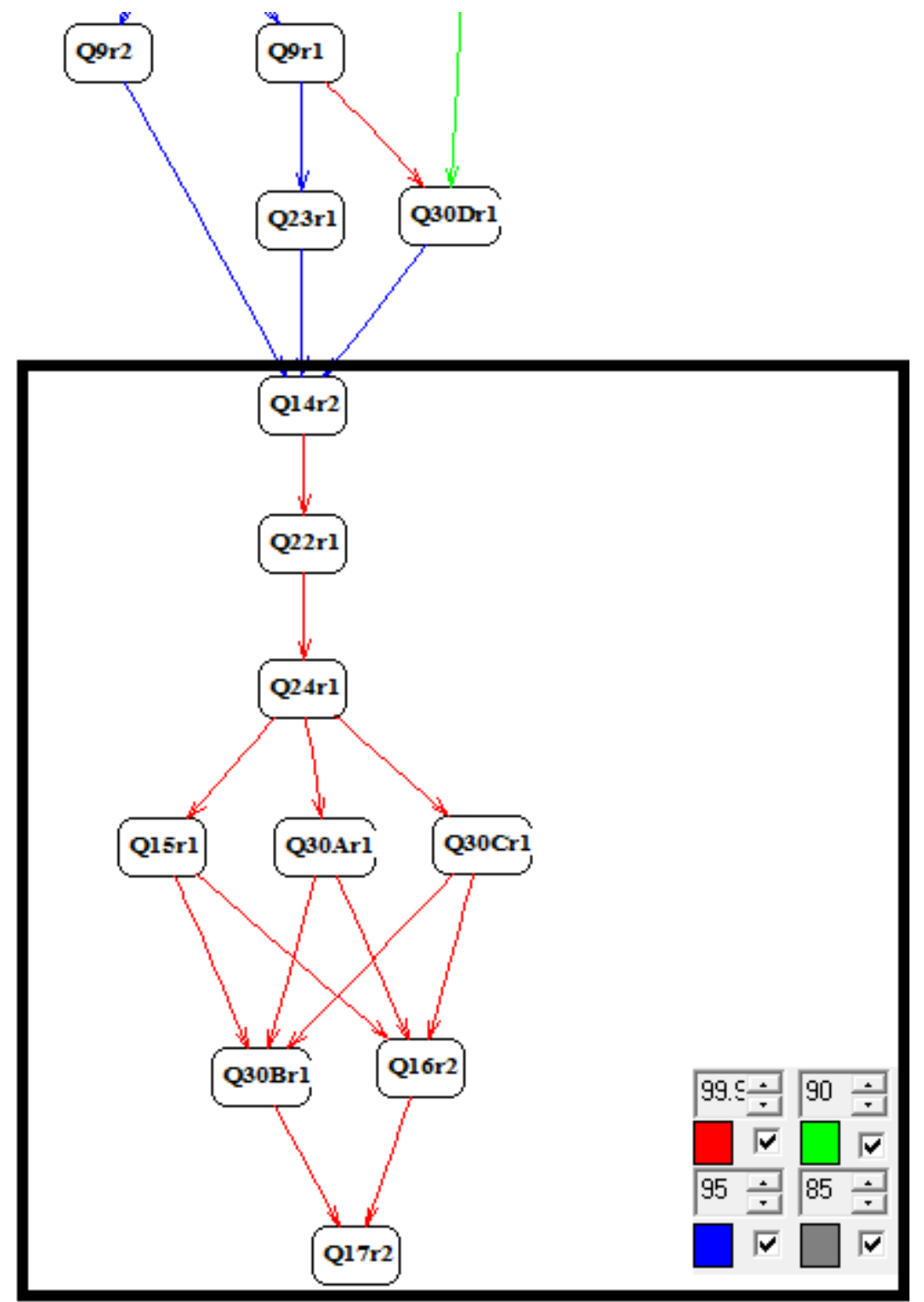


Figura 11: Grafo implicativo com as relações das variáveis indicativas de letramento financeiro

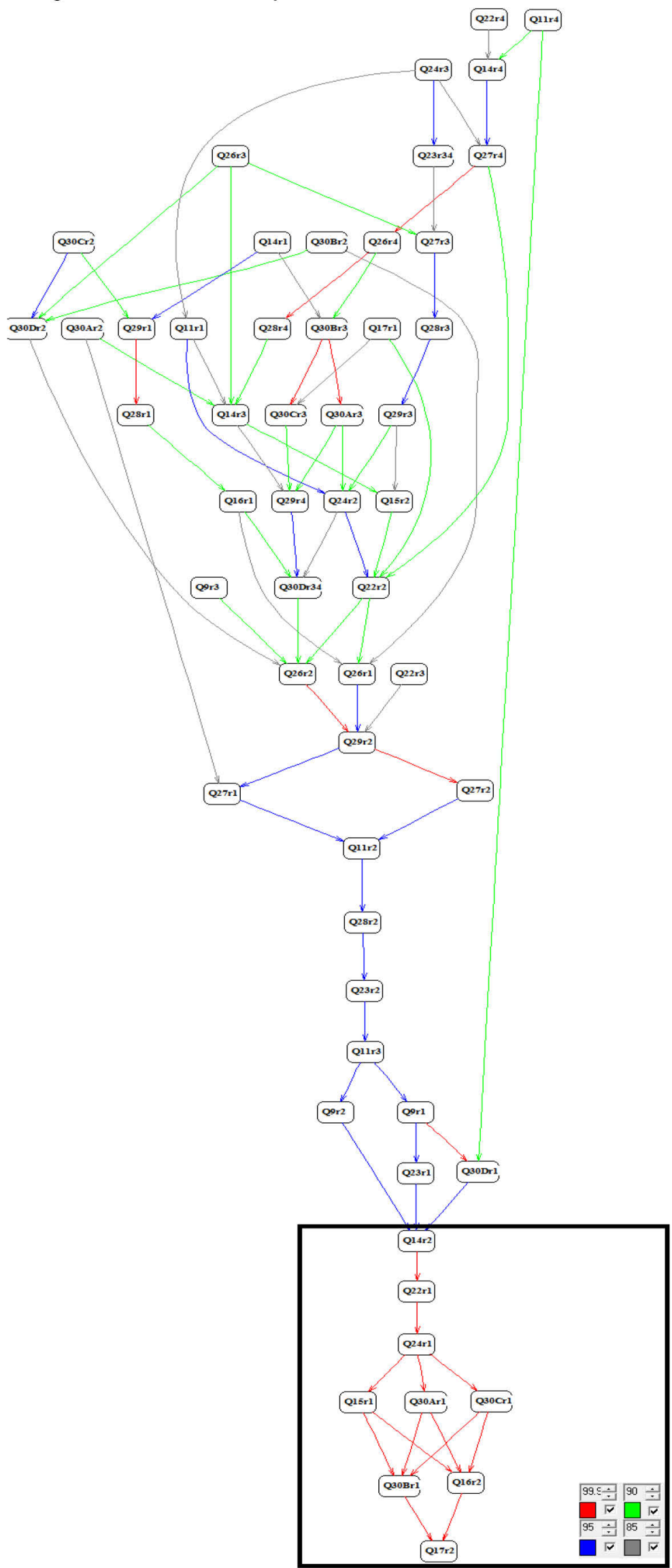


Apesar de todos os caminhos possiveis evidenciados no grafo, destacam-se aqui aqueles que, no nosso entendimento, apresentam percursos implicativos mais relevantes $(99,9$ de significância), que são ressaltados na Figura 8. Os caminhos construídos na Análise Estatística Implicativa são categorizados segundo um índice de significância determinado pelo software, com valores de 0 a 1 e que são categorizados em quatro níveis. A cor vermelha indica os níveis mais altos (99,9\%), enquanto que a cor cinza indica os níveis mais baixos (no caso, $85 \%)$

Nos seis caminhos em destaque na Figura 9, é interessante observar que todos eles fazem a associação de que os professores pertencentes à amostra pesquisada, ao prepararem as suas aulas de matemática financeira e que procuram conhecer pesquisas recentes acerca desse tema, tem um cuidado maior em relação à essa tarefa pedagógica. Os resultados demonstram que esses docentes, além de se preocuparem em explicar primeiro as noções de capitalização simples e composta envolvidas para depois propor situações-problema, se dedicam à complementação do conteúdo dessa disciplina que está presente nos livros didáticos. Notemos que estas relações reforçam aquelas identificadas na análise coesitiva.

Figura 11: Caminhos implicativos CI1 a CI6

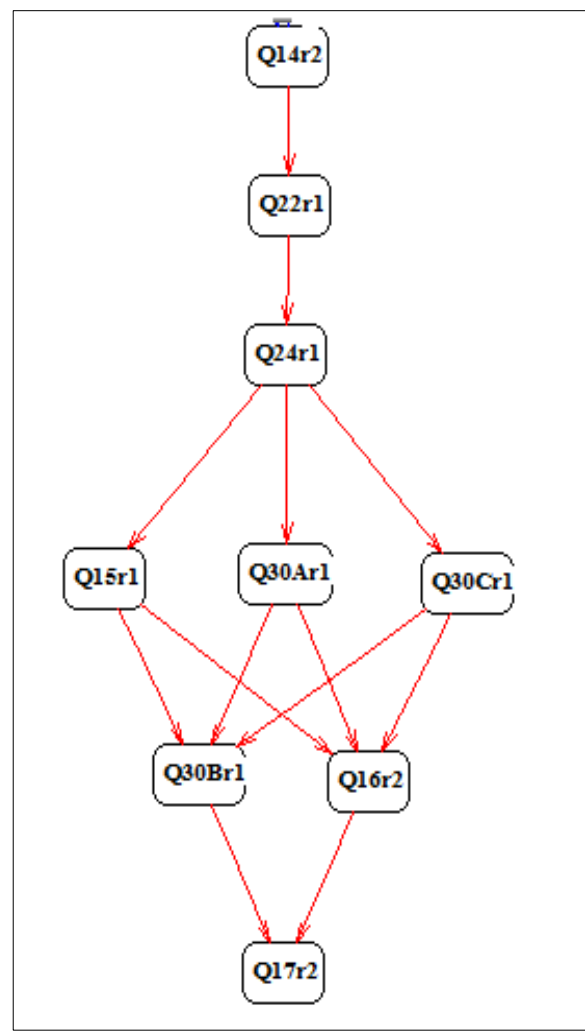

\begin{tabular}{|c|l|}
\hline Caminho & \multicolumn{1}{|c|}{ Variáveis relacionadas } \\
\hline $\mathrm{Cl} 1$ & $\begin{array}{l}\mathrm{Q} 14 \mathrm{r} 2 \rightarrow \mathrm{Q} 22 \mathrm{r} 1 \rightarrow \mathrm{Q} 24 \mathrm{r} 1 \rightarrow \mathrm{Q} 15 \mathrm{r} 1 \rightarrow \mathrm{Q} 30 \\
\mathrm{~b} 1 \rightarrow \mathrm{Q} 17 \mathrm{r} 2\end{array}$ \\
$\mathrm{Cl} 2$ & $\begin{array}{l}\mathrm{Q} 14 \mathrm{r} 2 \rightarrow \mathrm{Q} 22 \mathrm{r} 1 \rightarrow \mathrm{Q} 24 \mathrm{r} 1 \rightarrow \mathrm{Q} 30 \mathrm{cr} 1 \rightarrow \mathrm{Q} 30 \\
\mathrm{~b} 1 \rightarrow \mathrm{Q} 17 \mathrm{r} 2\end{array}$ \\
$\mathrm{Cl} 3$ & $\begin{array}{l}\mathrm{Q} 14 \mathrm{r} 2 \rightarrow \mathrm{Q} 22 \mathrm{r} 1 \rightarrow \mathrm{Q} 24 \mathrm{r} 1 \rightarrow \mathrm{Q} 30 \mathrm{ar} 1 \rightarrow \mathrm{Q} 16 \\
\mathrm{r} 2 \rightarrow \mathrm{Q} 17 \mathrm{r} 2\end{array}$ \\
$\mathrm{Cl} 4$ & $\begin{array}{l}\mathrm{Q} 14 \mathrm{r} 2 \rightarrow \mathrm{Q} 22 \mathrm{r} 1 \rightarrow \mathrm{Q} 24 \mathrm{r} 1 \rightarrow \mathrm{Q} 15 \mathrm{r} 1 \rightarrow \mathrm{Q} 16 \\
\mathrm{r} 2\end{array}$ \\
$\mathrm{Cl} 5$ & $\begin{array}{l}\mathrm{Q} 14 \mathrm{r} 2 \rightarrow \mathrm{Q} 22 \mathrm{r} 1 \rightarrow \mathrm{Q} 24 \mathrm{r} 1 \rightarrow \mathrm{Q} 30 \mathrm{cr} 1 \rightarrow \mathrm{Q} 16 \\
\mathrm{r} 2\end{array}$ \\
$\mathrm{Cl} 6$ & $\begin{array}{l}\mathrm{Q} 14 \mathrm{r} 2 \rightarrow \mathrm{Q} 22 \mathrm{r} 1 \rightarrow \mathrm{Q} 24 \mathrm{r} 1 \rightarrow \mathrm{Q} 30 \text { ar1 } \rightarrow \mathrm{Q} 30 \\
\mathrm{br} 1\end{array}$ \\
\hline
\end{tabular}

O caminho implicativo 1 evidencia que os professores que sabem que a educação financeira é ensinada no Japão, EUA e Europa; demonstram sucesso em relação à resolução do ítem b do 
problema proposto e vêem semelhanças entre a matematica financeira e a educação financeira. Isto, conforme já apontado na análise coesitiva, indica a coerência e consistência das respostas.

O CI 4 destaca-se pelo fato de que, apesar de todas as implicações contempladas no CI 1, a ENEF ainda não é conhecida pelos docentes participantes da amostra pesquisada. Já no caminho implicativo 3 temos o reforço do percentual de acerto no tocante à resolução do problema proposto (questão 30, itens b e c). Os caminhos implicativos 4, 5 e 6 ratificam e corroboram todas as conclusões já expostas.

A relação a ser destacada nessa análise vem da observação de que todos os caminhos de 1 a 6 terminam na mesma variável: Q17r2, que representa a resposta "matemática financeira e educação financeira são quase a mesma coisa". Tal resultado é bastante importante e nos permite inferir que a origem de muitas das dificuldades para a abordagem da educação financeira a partir da consideração de pressupostos da matemática crítica vem dessa assimilação. Dessa forma, podemos supor que, nestes casos, a busca por contextos reais ou realísticos pode ser considerada não essencial para a resolução de problemas da matemática financeira, sem um questionamento que permita uma reflexão efetiva sobre o que se está analisando.

\section{Considerações}

De acordo com a OCDE (2004), a educação financeira pode ser definida como sendo o processo por meio do qual os cidadãos melhoram sua compreensão sobre produtos financeiros, seus conceitos e riscos. Dessa forma, com informação e recomendações claras, eles podem desenvolver as habilidades e a confiança necessária para tomarem decisões fundamentadas e com segurança, melhorando assim o seu bem estar financeiro.

Diante desse contexto é que emerge a questão central da pesquisa da qual este artigo é um recorte: Será que os professores, bacharéis ou licenciados em matemática que ministram a disciplina de matemática financeira no Ensino Médio estão devidamente letrados financeiramente ao nível necessário para os propósitos da estratégia nacional de educação financeira?

A hipótese levantada é a de que a educação financeira, tão importante para o cidadão, só pode ser ensinada nas escolas por meio de um corpo docente devidamente letrado. Isso implica em que o professor conheça e domine os conceitos de matemática financeira, além de conhecer e 
aplicar em suas aulas os pressupostos da Matemática Crítica. Skovsmose (2007) chama a atenção para a ideologia da certeza na Matemática e destaca que esta ciência não pode ser e ter a palavra final, porém deve servir para construir argumentos.

Observamos que as principais variáveis que permitiram construir um retrato do letramento financeiro dos professores respondentes foram aquelas identificadas pela análise implicativa, particularmente o grafo ilustrado na Figura 11, e que também foram analisadas em termos coesitivos. Tais relações indicam que é necessário que se considere a preocupação em relação à contextualização das situações abordadas em ambiente escolar implicando, necessariamemnte, em um melhor letramento do corpo docente que leciona matemática financeira para os propósitos do ensino e aprendizagem de educação financeira.

Fazemos a hipótese de que os professores podem construir competências necessárias para a concepção e gestão de situações de aprendizagem que favoreçam o letramento financeiro dos alunos a partir da distinção efetiva entre Matemática Financeira e Educação Financeira. A Figura 11 ressalta de forma bastante importante o papel da assimilação entre as duas.

\section{Referências}

ALMEIDA, A. C. Trabalhando Matemática Financeira em uma sala de aula do Ensino Médio da Escola Pública. 2004. 112 f. Dissertação (Mestrado Acadêmico em Educação). Universidade Estadual de Campinas - UNICAMP. Campinas, São Paulo, 2004.

ALMOULOUD, S. a. L' analyse statistique de données multidimensionnlles: outil révelateur des conceptions d' enseignants em formation. In: Encontro Chic, São Paulo, Anais... São Paulo, 2005.

BOLIVAR, A. (org.). Profissão Professor: o itinerário profissional e a construção da escola.

SOUZA, G.C.C. (trad). Bauru, SP: EDUSC, 2002.

DUARTE, P. C. X; VIANA, D. S; TASSOTE, E. M; DIAS, M. V. Matemática Financeira: um alicerce para o exercício da cidadania. Revista Núcleos. Fundação Educacional de Ituverava. São Paulo, v.9, n.1, 2012, p. 195-207.

GRANDO, N. I; SCHNEIDER, I. J. Matemática Financeira: alguns elementos históricos e contemporâneos. Revista Zetetiké - FE. UNICAMP. Campinas, São Paulo, v. 18, n. 33, 2010, p. 43-62.

GRAS, R.; KUNTZ, P.; BRIAND, H. The foundations of the Implicative Statistical Analysis and some extension for data mining. n. 154, 2001, p. 9-29.

GRAS, R; ALMOULOUD, S.; A implicação estatística usada como ferramenta em um exemplo de análise de dados multidimensionais. Revista Educação Matemática Pesquisa. 
Programa de Estudos Pós-Graduados em Educação Matemática - PUCSP. São Paulo: EDUC, v. 4, n. 2, 2002, p. 75-88.

HERMÍNIO, P. H. Matemática Financeira: um enfoque da resolução de problemas como metodologia de ensino e aprendizagem. 2008. 244 f. Dissertação (Mestrado Acadêmico em Educação Matemática). Universidade Estadual Paulista - UNESP. Rio Claro, São Paulo, 2008.

HOFFMANN, R. M. Educação matemática, contexto e educação financeira. In: XIII Conferência Interamericana de Educação Matemática - CIAEM. Recife, Pernambuco, 2011, p. 1-12.

HOFFMANN, R. M.; MORO, M. L. F. Educação matemática e educação financeira: perspectivas para a ENEF. Revista Zetetiké - FE. UNICAMP, Campinas, São Paulo, v. 20, n. 38,2012 , p. 37-54.

KERN, D. T. B. Uma Reflexão sobre a importância de Inclusão de Educação Financeira na Escola Pública. 2009. 199 f. Dissertação (Mestrado Profissional em Ensino de Ciências Exatas). Centro Universitário Univates. Rio Grande do Sul, Porto Alegre, 2009.

KLEIMAN, A. Preciso ensinar o letramento? Não basta ensinar a ler e a escrever? São Paulo: Produção Editorial, 2005.

OCDE. Organização de Cooperação e de Desenvolvimento Econômico. Recommendation on Principles and Good Pratices for Financial Education and Awareness. Recomendation of the Council. OCDE. Paris, 2004. Disponível em: <http://www.oecd.org/>. Acesso em: 10 jan. 2013.

PELICIOLI, A. F. A Relevância da Educação Financeira na Formação de Jovens. 2011. 130 f. Dissertação (Mestrado Acadêmico em Educação em Ciências e Matemática). Pontifícia Universidade Católica do Rio Grande do Sul - PUC/RS. Rio Grande do Sul, 2011.

RIBEIRO, C.A; VIEIRA, K.M.; SANTOS, J.H.A; TRINDADE, L.L.; MALLMANN,E.I. Finanças Pessoais: análise dos gastos e da propensão ao endividamento em estudantes de administração. In: XII SEMEAD/FEA/USP. São Paulo, 2009, p. 1-18.

ROSSETI JUNIOR, H; SCHIMIGUEL, J. Educação matemática financeira: conhecimento financeiros para a cidadania e inclusão. Artigo Científico. Revista Científica Internacional Science Place. Espanha, v. 2, n. 9, 2009, p. 1-13.

SÁ, C. A. Fluxo de Caixa: A Visão da Tesouraria e da Controladoria. 2. ed. São Paulo: Atlas, 2008.

SAVOIA, J. R. F; SAITO, A. T; SANTANA, F. A. Paradigmas da educação financeira no Brasil. Revista de Administração Pública, Rio de Janeiro, v. 41, n. 6, nov./dez. 2007, p. 1121-1141. Disponível em: $\quad<\mathrm{http}: / / \mathrm{www}$.scielo.br/scielo.php?pid=S003476122007000600006\&script=sci_arttext $>$. Acesso em: 8 jul. 2013. 
SCHENEIDER, I. J. Matemática Financeira: um conhecimento importante e necessário para a vida das pessoas. 2008. 112 f. Dissertação (Mestrado Acadêmico em Educação). Universidade de Passo Fundo. Rio Grande do Sul, 2008.

SILVA, E. D. Gestão em Finanças Pessoais: uma metodologia para adquirir educação e saúde financeira. São Paulo: Qualitymark, 2004.

SKOVSMOSE, O.. Educação Crítica: Incerteza, Matemática, Responsabilidade. São Paulo: Cortez, 2007.

STEPHANI, M. Educação Financeira: uma perspectiva interdisciplinar na construção da autonomia do aluno. 2005. 79 f. Dissertação (Mestrado Acadêmico em Educação em Ciências e Matemática). Pontifícia Universidade Católica do Rio Grande do Sul - PUC/RS. Rio Grande do Sul, 2005.

TOMMASI, A; LIMA, F de. Viva Melhor Sabendo Administrar suas Finanças. São Paulo: Saraiva, 2007.

UNESCO. Aspects of Literacy Assessment: Topics and issues from the UNESCO Expert Meeting. 2005. Disponível em: <http://unesdoc.unesco.org/images/0014/ 001401/140125eo.pdf>. Acesso em: 12 nov. 2013.

VIEIRA, L. C. A Matemática Financeira no Ensino Médio e sua Articulação com a Cidadania. 2010. 94 f. Dissertação (Mestrado Profissional em Educação Matemática). Universidade Severino Sombra - USS. Rio de Janeiro, 2010. 